\title{
Luteolin supports osteogenic differentiation of human periodontal ligament cells
}

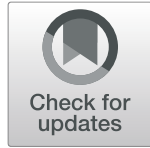

He Quan ${ }^{\dagger}$, Xiaopeng Dai ${ }^{\dagger}$, Meiyan Liu, Chuanjun Wu and Dan Wang ${ }^{*}$ (i)

\begin{abstract}
Background: Previous research revealed that luteolin could improve the activation of alkaline phosphatase (ALP) and osteocalcin in mouse osteoblasts. We aimed to determine the effect of luteolin on osteogenic differentiation of periodontal ligament cells (PDLCS).

Methods: Cultured human PDLCs (HPDLCs) were treated by luteolin at $0.01,0.1,1,10,100 \mu \mathrm{mol} / \mathrm{L}$, Wnt/ $\beta$-catenin pathway inhibitor (XAV939, $5 \mu \mathrm{mol} / \mathrm{L}$ ) alone or in combination with $1 \mu \mathrm{mol} / \mathrm{L}$ luteolin. Immunohistochemical staining was performed to ensure cells source. Cell activity and the ability of osteogenic differentiation in HPDLCs were determined by MTT, ALP and Alizarin Red S staining. Real-time Quantitative PCR Detecting System (qPCR) and Western blot were performed to measure the expressions of osteogenic differentiation-related genes such as bone morphogenetic protein 2 (BMP2), osteocalcin (OCN), runt-related transcription factor 2 (RUNX2), Osterix (OSX) and Wnt/ $\beta$-catenin pathway proteins members cyclin D1 and $\beta$-catenin.
\end{abstract}

Results: Luteolin at concentrations of $0.01,0.1,1,10,100 \mu \mathrm{mol} / \mathrm{L}$ promoted cell viability, ALP activity and increased calcified nodules content in HPDLCs. The expressions of BMP2, OCN, OSX, RUNX2, $\beta$-catenin and cyclin D1 were increased by luteolin at concentrations of $0.01,0.1,1 \mu \mathrm{mol} / \mathrm{L}$, noticeably, $1 \mu \mathrm{mol} / \mathrm{L}$ luteolin produced the strongest effects. In addition, XAV939 inhibited the expressions of calcification and osteogenic differentiation-related genes in HPDLCs, and $1 \mu \mathrm{mol} / \mathrm{L}$ luteolin availably decreased the inhibitory effect.

Conclusion: $1 \mu \mathrm{mol} / \mathrm{L}$ luteolin accelerated osteogenic differentiation of HPDLCs via activating the Wnt/ $\beta$-catenin pathway, which could be clinically applied to treat periodontal disease.

Keywords: Periodontal ligament, Cell differentiation, Wnt signaling pathway, Osteogenesis, Luteolin

\section{Introduction}

As a common oral disease, periodontal disease is a main cause to tooth loss and could lead to local or even systemic effects [1]. Periodontal disease mainly promotes the regeneration of periodontal tissue, producing a certain number of healthy periodontal ligament cells (PDLCs) functioning as the primary basis for the repair of periodontal disease [2]. Derived from the mesoderm, PDLCs are the most abundant cells in the periodontal membrane and also the main cell source for the attachment between gingiva and root surface after periodontal treatment [3]. Additionally, PDLCs can not only promote the formation of new main fibers and cementum, but also play a vital role in the reconstruction of alveolar

\footnotetext{
* Correspondence: danw_wangdd@163.com

${ }^{\dagger}$ He Quan and Xiaopeng Dai contributed equally to this work.

Economic \& Technological Development Area Clinic, Yantai Stomatological Hospital, No. 11 Songshan Road, Yantai 264000, Shandong Province, China
}

bone [4]. The osteogenic differentiation of PDLCs is also essential in the regeneration of periodontal tissues [5]. Among the conduction pathways, Wnt/ $\beta$-catenin signaling pathway, which plays a significant role in embryonic development, organ formation, tumor formation and bone reconstruction [6], could activate the expression of downstream target gene cyclin D1 in the nucleus, promotes the activity of osteoblasts and the mineralization of extracellular matrix by regulating directional differentiation of osteoblasts and the expressions of specific genes [7].

It has been reported that luteolin, which often exists as glycosylation in nature, could affect osteogenic differentiation [8]. Previous studies also showed that luteolin was a natural tetrahydroxyl flavonoid compound with a molecular weight of $286.23 \mathrm{kD}$ [9]. luteolin was initially isolated from the leaves, stems and branches of resedaceae, however, researchers found that luteolin could also

(c) The Author(s). 2019 Open Access This article is distributed under the terms of the Creative Commons Attribution 4.0 International License (http://creativecommons.org/licenses/by/4.0/), which permits unrestricted use, distribution, and reproduction in any medium, provided you give appropriate credit to the original author(s) and the source, provide a link to the Creative Commons license, and indicate if changes were made. The Creative Commons Public Domain Dedication waiver (http://creativecommons.org/publicdomain/zero/1.0/) applies to the data made available in this article, unless otherwise stated. 
be extracted from a variety of natural medicinal materials, vegetables and fruits such as honeysuckle, wormwood, celery and cabbage [10]. In pharmacology, luteolin is a multifunctional complex that has a positive medicinal effect, for example, anti-cancer, anti-inflammatory, regulating immunity function, resisting oxidation and reducing osteoclast activity [11].

In treating periodontal disease, as auxiliary measures to oral mechanical treatment, pharmaceutical drugs can improve therapeutic efficacy. However, some western medicines such as antibiotics and other commonly used drugs have certain toxic and side effects, thus, as antibiotic resistance becomes stronger, their effectiveness in treating periodontal disease is limited to some extent [12]. Studies have proved that various traditional Chinese medicine herbs had specific therapeutic effects on treating periodontal diseases such as radix scutellariae [13] and cinnamaldehyde [14].

As luteolin could protect human bronchial epithelial cells via activating nuclear factor erythroid 2-related factor 2 (Nrf2) pathway, some scholars believed that luteolin can be used as a medicine for the prevention and treatment of lung cancer [15]. Nash et al. [16] pointed out that the luteolin extracted from tea could increase the mineral content in human osteoblasts. In addition, according to the study of Abbasi et al. [17], a low concentration of luteolin could protected osteoblasts from oxidative stress induced by high glucose. In dental field, Liu L et al. [18] found that luteolin could effectively maintain the pluripotency of PDLC by activating related pathways. Though, studies on the application of luteolin in osteoblastic cells increased gradually, the effect of luteolin on osteoblastic differentiation of PDLCs has not yet been investigated. Therefore, this study mainly explored the effect of different concentrations of luteolin on human PDLCs (HPDLCs), and analyzed its effects on osteogenic differentiation and Wnt/ $\beta$-catenin signaling pathway. Our findings provide a new understanding on the treatment of periodontal diseases.

\section{Methods}

This study was approved by the Ethics Committee of Yantai Stomatological Hospital, and all donors signed the informed consent.

\section{Cell culture}

HPDLCs were obtained from healthy human third molars, the teeth came from six donors aged between 18 and 35 years old. All patients had their teeth removed due to orthodontic requirement, and they did not have concomitant dental, pulp or periodontal diseases. The teeth were washed 3 times by sterile phosphate buffer saline (PBS), and then the periodontal ligament was separated from the middle third of the root surface using a blade in an aseptic ultra-clean table, and the PDL was cut into thin slices of $1 \mathrm{~mm}^{3}$. The PDL tissue was cultured in dulbecco's modified eagle medium (DMEM, Gibco, Carlsbad, USA) containing 10\% fetal bovine serum (FBS, Millipore, USA), $100 \mathrm{mg} / \mathrm{mL}$ streptomycin and $100 \mathrm{U} / \mathrm{mL}$ penicillin (Gibco, USA) at $37^{\circ} \mathrm{C}$ in a humid environment with $5 \% \mathrm{CO}_{2}$. HPDLCs passage was performed by digestion with $0.05 \%$ ethylene diamine tetraacetic acid (EDTA) plus $0.25 \%$ trypsin (Sigma, USA). The medium was changed every 3 days until the cells were separated from the tissues and filled $80 \%$ of the well plate. Cells used in each experiment came from only one donor from his third to sixth generations.

\section{Cell identification}

To determine the source and characteristic of HPDLCs, immunofluorescence detection was performed on the HPDLCs at 3rd passage. Preliminary experimental analysis showed that 5000 cells per well plate in a 24-well plate were optimal for cell identification. Briefly, $1.5 \mathrm{~mL}$ DMEM medium containing 10\% FBS was added into the cells, which were washed twice by PBS buffer, fixed with $4 \%$ paraformaldehyde for $30 \mathrm{~min}$ at room temperature and blocked by human mesenchymal stem cell characterization kit (Millipore, Billerica, MA, USA). Next, vimentin and cell keratin (mouse, vimentin BM0135, cytokeratin BM0030, 1: 200, BosterBio, Wuhan, China) were added into the cells and held overnight at $4{ }^{\circ} \mathrm{C}$. After being rinsed in PBS buffer for 3 times, the cells were incubated with fluorescein isothiocyanate and secondary antibody horseradish peroxidase-conjugated goat anti-mouse IgG (A0216, 1:500, Beyotime, Suzhou, China) at room temperature for $45 \mathrm{~min} \mathrm{[19].} \mathrm{Then,} \mathrm{the} \mathrm{cells} \mathrm{were} \mathrm{redyed} \mathrm{with} \mathrm{4,} \mathrm{6-}$ diamino-2-phenylindole (DAPi, 1:100, Vector Laboratories, Burlingame, CA, USA). Fluorescence microscopy (BX-41, Olympus Optical, Tokyo, Japan) was used for image analysis.

\section{Treatment of cells}

HPDLCs at a density of $2 \times 10^{5} / \mathrm{mL}$ were inoculated on three 96-well plates [20] in an incubator at $37^{\circ} \mathrm{C}$ with $5 \%$ $\mathrm{CO}_{2}$ until 70 80\% confluence was reached. Each group in this study had six multiple holes and the surrounding holes were filled with sterile PBS solution. Luteolin (batch number: 111520-200,201, purity> 99\%, China Food and Drug Administration, Beijing, China) was dissolved by dimethyl sulfoxide (DMSO, Sigma, USA), and the different concentrations $(0.01,0.1,1,10,100 \mu \mathrm{mol} / \mathrm{L})$ of luteolin $[21,22]$, Wnt $/ \beta$-catenin pathway inhibitor XAV939 $(5 \mu \mathrm{mol} / \mathrm{L}$, purity $>98 \%$, Sigma, USA) [23], $1 \mu \mathrm{mol} / \mathrm{L}$ of luteolin in combination with XAV939 (luteolin was first incubated for $20 \mathrm{~min}$ and added with XAV939) were added into well plates and served as positive groups. In addition, untreated 
cells in control group were incubated with PBS buffer and considered as a negative control, compared with other groups in this study. The treated cells used in the following experiments were confirmed by preliminary experiments, as well as the time frame had the best experimental effect at the corresponding treatment time.

\section{Cell viability analysis}

3-(4),-5-dimethylthiazole-2-acyl)-2, 5-diphenyltetrazole ammonium bromide (MTT) assay was used to determine the viability of HPDLCs. After 24, 48 and $72 \mathrm{~h}$ of treatment, $10 \mu \mathrm{L}$ MTT $(1 \mathrm{mg} / \mathrm{mL}$, Sigma, USA) was added to the cells and held for $4 \mathrm{~h}$ in the dark at $37^{\circ} \mathrm{C}$. Then, the formazan crystals dissolved in $200 \mathrm{~mL}$ DMSO were added to each well and held for $10 \mathrm{~min}$. Finally, the optical density (OD) of each well was measured at $490 \mathrm{~nm}$ wavelength by enzyme-linked immunoassay (ELX808, BioTek, Vermont, USA), and the average value was calculated.

\section{Alkaline phosphatase (ALP) activity analysis}

Alkaline phosphatase (ALP) activity analysis was conducted to determine the osteogenic differentiation ability of HPDLCs. Cells were cultured in differentiation medium (Sigma, USA) containing DMEM medium (10\% FBS), $10^{-7} \mathrm{~mol} / \mathrm{L}$ dexamethasone, $50 \mu \mathrm{g} / \mathrm{mL}$ ascorbic acid $\mathrm{Vc}$ and $10 \mathrm{mmol} / \mathrm{L}$ sodium $\beta$-glycerophosphate for $72 \mathrm{~h}$ at $37^{\circ} \mathrm{C}$ with $5 \% \mathrm{CO}_{2}$. After $72 \mathrm{~h}$ of incubation, the cells were rinsed 3 times with PBS buffer and fixed with $4 \%$ polyformaldehyde at $4{ }^{\circ} \mathrm{C}$ for $10 \mathrm{~min}$. Next, BCIP/NBT alkaline phosphatase coloring kit (Beyotime, Suzhou, China) was used for ALP staining according to the manufacturer's instructions. After being incubated with luteolin for $3 \mathrm{~d}$, the ALP activity of HPDLCs was measured using ALP kit (Jiancheng Bioengineering, Nanjing, China) and enzyme-linked immunoassay (ELX808, BioTek) at $520 \mathrm{~nm}$ wavelength.

\section{Mineralization characteristics analysis}

Alizarin Red S staining was used to determine content of calcified nodules in HPDLCs. The HPDLCs treated for $24 \mathrm{~h}$ were cultured in a $35 \mathrm{~mm}$ Petri dish containing differentiation medium, which was changed every 2 days during 5 weeks. When mineralized nodules were formed, the cells were fixed with $4 \%$ polyformaldehyde for 30 min, stained by $0.1 \%$ Alizarin Red S (Sigma, USA) at $\mathrm{pH}$ 4.3 for $30 \mathrm{~min}$ at room temperature and rinsed with deionized water. The staining results were observed under a microscope using a digital camera (Nikon, Japan). Cetylpyridine chloride (CPC) method was applied to detect the content of calcium deposition, and the absorbance was measured using a multifunctional microplate reader (M1000 Pro, TECAN, Switzerland) at $560 \mathrm{~nm}$.
Quantitative polymerase chain reaction (qPCR)

$\mathrm{qPCR}$ assay was performed to detect the expressions of osteogenic differentiation-related genes in HPDLCs. After $72 \mathrm{~h}$ of treatment, Trizol reagent (Invitrogen, Carlsbad, California, USA) was used to extract the total RNA from the cells, and the purity and concentration of RNA were determined by spectrophotometer (Nano Drop Technologies ND-1000, Wilmington, Delaware, USA). Total RNA $(1 \mu \mathrm{g})$ was extracted and synthesized into cDNA by performing reverse transcription at $37^{\circ} \mathrm{C}$ for $15 \mathrm{~min}$ using PrimeScript ${ }^{\mathrm{six}} \mathrm{RT}$ reagent kit (Takara, Japan). SYBR PremixEx Taq Kit (TaKaRa, Japan) was used to carry out qPCR assays, and the reaction conditions were set as follows: predenaturation at $94{ }^{\circ} \mathrm{C}$ for $30 \mathrm{~s}$, denaturation at $94{ }^{\circ} \mathrm{C}$ for $10 \mathrm{~s}$, annealing at $60^{\circ} \mathrm{C}$ for $30 \mathrm{~s}$, extension at $72^{\circ} \mathrm{C}$ for $3 \mathrm{~min}$ and final extension at $72^{\circ} \mathrm{C}$ for $10 \mathrm{~min}$. The primer base sequences (Gene Pharma, Shanghai, China) used were bone morphogenetic protein 2 (BMP2), osteocalcin $(\mathrm{OCN})$, runt-related transcription factor 2 (RUNX2), Osterix (OSX), cyclin D1 and $\beta$ catenin and listed in Table 1 . Each reaction was carried out for three times using glyceraldehyde-3phosphate dehydrogenase (GAPDH) as an internal control, and the data were analyzed by the $2^{-\Delta \Delta C T}$ method [24].

\section{Western blotting (WB) analysis}

Western blotting (WB) analysis was performed to detect proteins related to osteogenic differentiation and Wnt/ $\beta$-catenin pathway. After 3 days of treatment, all proteins were extracted from cells on ice by RIPA lysis buffer (Beyotime, Suzhou, China) containing 1 $\mathrm{mmol} / \mathrm{L}$ phenylmethanesulfonyl fluoride (PMSF) and centrifuged for $20 \mathrm{~min}(10,000 \mathrm{~g})$ at $4{ }^{\circ} \mathrm{C}$. Protein content was determined by bicinchoninic acid (BCA) protein assay kit (Fude, China). A total of $30 \mu$ g protein lysates were separated by $8 \%$ sodium dodecyl sulfate polyacrylamide gel electropheresis (SDS-PAGE, Beyotime, China) and transferred to polyvinylidene fluoride (PVDF, Beyotime, China) membrane, which was blocked for $2 \mathrm{~h}$ at

Table 1 Primer base sequence

\begin{tabular}{lll}
\hline Gene & Forward (5'-3') & Reverse (5'-3') \\
\hline BMP2 & TATTTGGATAAGAACCAGACATTG & GAAAGAAGACAACAAACCATCA \\
OCN & AGCAAAGGTGCAGCCTTGT & GCGCCTGGGTCTCTCACT \\
RUNX2 & GAGATTTGTGGGCCGGAGTG & CCTAAATCACTGAGGCGGTC \\
OSX & ACCTACCCATCTGACTTGCTC & CCACTATTTCCCACTGCCTTG \\
Cyclin D1 & TGATGCTGGGCACTTCATCTG & TCCAATCATCCCGAATGAGAGTC \\
B-catenin & AAAATGGCAGTGCGTTAG & TाTGAGGCAGTCTGTCGTA \\
GAPDH & AACGGATTGGTCGTATTGG & TGGAAGATGGTGATGGGATT \\
\hline
\end{tabular}


room temperature in 3\% skimmed milk. Primary antibodies (BMP2 (ab14933, 1:2000, abcam, USA; https://www .abcam.cn/bmp2-antibody-ab14933.html), OCN (ab13420, 1:1000, abcam, USA; https://www.abcam.cn/osteocalcinantibody-ocg3-ab13420.html), RUNX2 (ab76956, 1:1000, abcam, USA; https://www.abcam.cn/runx2-antibody-ab76 956.html), Osterix (OSX, ab22552, 1:2000, abcam, USA; https://www.abcam.cn/sp7-osterix-antibody-chip-grade-ab 22552.html), cyclin D1 (ab134175, 1:2000, abcam, USA; https://www.abcam.cn/cyclin-d1-antibody-epr2241-c-termi nal-ab134175.html), $\beta$-catenin (ab8226, 1:2000, abcam, USA; https://www.abcam.cn/beta-actin-antibody-mabcam8226-loading-control-ab8226.html) and GAPDH (ab8245, 1:2000, abcam, USA; https://www.abcam.cn/gapdh-antibody-6c5-loading-contr ol-ab8245.html)) were added to the membrane and held overnight at $4{ }^{\circ} \mathrm{C}$. After washing the cells with TBST for three times, goat anti-mouse IgG antibody labeled with horseradish peroxidase (A0216, 1:1000; Beyotime, Suzhou, China; https://www.beyotime.com/product/A0216.htm) and goat anti-rabbit IgG H\&L (HRP) (ab205718, 1:2000, abcam, USA; https://www.abcam.cn/goat-rabbit-igg-hl-hrp-ab20571 8.html) were added and held for $2 \mathrm{~h}$ at room temperature. ECL chemiluminescence kit (Millipore,
USA) was used for the exposure of the membrane, and Bio-Rad ChemiDoc XRS + Imaging System was used to analyse the signal intensity of gel band.

\section{Statistical analysis}

SPSS 20.0 software was used for statistical analysis. Metrological data were expressed by mean \pm standard deviation (SD). Before t-test, Shapiro-Wilk method was used to analyze whether the data in this study conform to normal distribution and whether the data were in line with the normal distribution. The difference between groups was analyzed by t-test or one-way ANOVA with the LSD test. The difference was defined as statistically significant when $P<0.05$.

\section{Results}

Characteristics of HPDLCs and effect of luteolin on cell activity

The results of immunofluorescence detection showed that vimentin staining was positive, while keratin staining was negative in HPDLCs (Fig. 1a). After 24, 48, $72 \mathrm{~h}$ of luteolin treatment, the results of MTT assay showed that luteolin at different concentrations $(0.01,0.1,1,10,100 \mu \mathrm{mol} / \mathrm{L})$ significantly increased the viability of HPDLCs $(P<0.001)$,

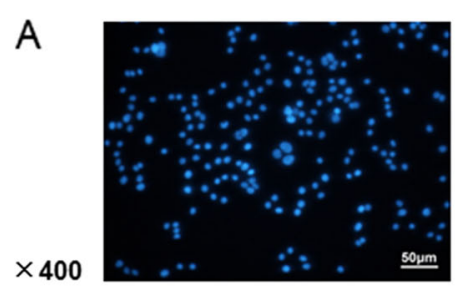

DAPi 1

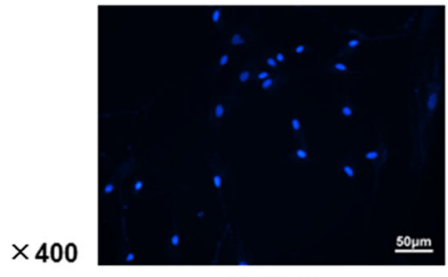

DAPi 2

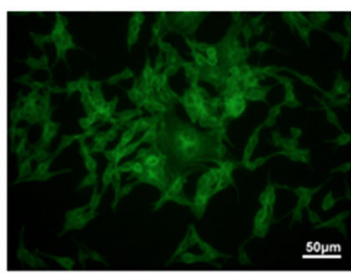

Vimentin

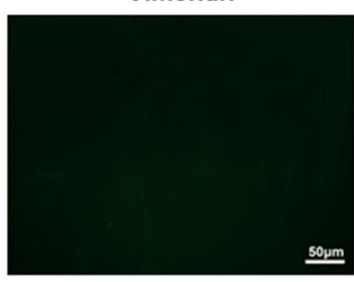

Cytokeratin

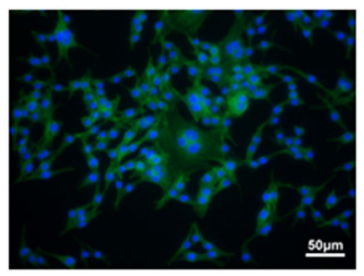

Vimentin-DAPi 1

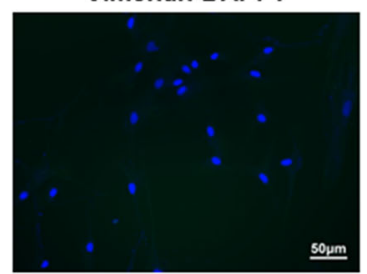

Cytokeratin-DAPi 2

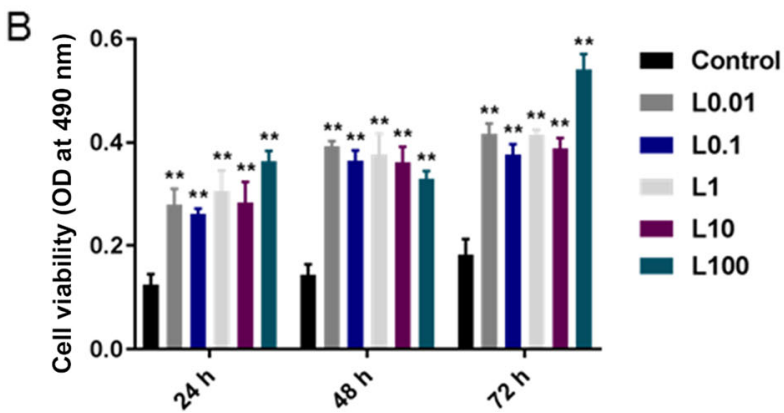

Fig. 1 a Result of immunohistochemical staining in HPDLCs $(\times 400)$ : vimentin staining was positive but keratin staining was negative. b MTT assay was performed to detect the effects of luteolin $(L)$ at different concentrations $(0,0.01,0.1,1,10,100 \mu \mathrm{mol} / \mathrm{L})$ on the viability of $\mathrm{HPDLCs}$ after 24,48 , and $72 \mathrm{~h}$ of treatment. ${ }^{* *} P<0.001$, vs. Control 
and no obvious difference was identified in the function of luteolin at different concentrations on HPDLCs proliferation at the same time point (Fig. 1b).

Effect of luteolin on osteogenic differentiation of HPDLCs The data in our study showed that different concentrations $(0.01,0.1,1,10,100 \mu \mathrm{mol} / \mathrm{L})$ of luteolin significantly enhanced ALP activity $(P<0.001)$ and increased the content of calcified nodules in HPDLCs $(P<0.001)$. Moreover, low concentration $(0.01,0.1,1,10 \mu \mathrm{mol} / \mathrm{L})$ produced a stronger effect than high concentration at $100 \mu \mathrm{mol} / \mathrm{L}$ $(P<0.05)$ and luteolin at $1 \mu \mathrm{mol} / \mathrm{L}$ had the strongest effect (Fig. 2a, b and c).

Effects of luteolin on the expressions of genes related to osteogenic differentiation and Wnt/B-catenin pathway protein of HPDLCs

Results of qPCR and WB analysis indicated that the relative mRNA and protein expressions of BMP2, OSX and $\mathrm{OCN}$ were significantly increased by luteolin at concentrations of $0.01,0.1,1$ and $10 \mu \mathrm{mol} / \mathrm{L}(P<0.001)$, and the expression of RUNX2 was greatly increased by luteolin at concentrations of $0.01,0.1$, and $1 \mu \mathrm{mol} / \mathrm{L} \quad(P<0.05)$.
However, high concentration of luteolin $(100 \mu \mathrm{mol} / \mathrm{L})$ had no significant effect on the relative mRNA and protein expressions of genes related to osteogenic differentiation (Fig. 3a, b and c). Thus, $1 \mu \mathrm{mol} / \mathrm{L}$ luteolin could produce the optimal effect on the osteoblastic differentiation. Furthermore, the relative mRNA and protein expressions of $\beta$-catenin and cyclin D1 were significantly increased by $1 \mu \mathrm{mol} / \mathrm{L}$ luteolin $(P<0.001$, Fig. 3d, e and f).

\section{Effect of Wnt/ $\beta$-catenin pathway inhibitor XAV939 on HPDLCs}

From the data of Alizarin Red S staining assay, $1 \mu \mathrm{mol} / \mathrm{L}$ luteolin promoted the calcification of HPDLCs $(P<$ $0.001)$, while XAV939 inhibited the calcification of cells $(P<0.001)$. Thus, luteolin could effectively limit the inhibiting action of XAV939 $(P<0.001$, Fig. $4 \mathrm{a}$ and $\mathrm{b})$.

Effect of Wnt/ß-catenin pathway inhibitor XAV939 on the expression of gene related to osteogenic differentiation The results of qPCR and WB assay showed that $1 \mu \mathrm{mol} /$ L luteolin significantly increased the relative mRNA and protein expressions of osteogenic differentiation-related

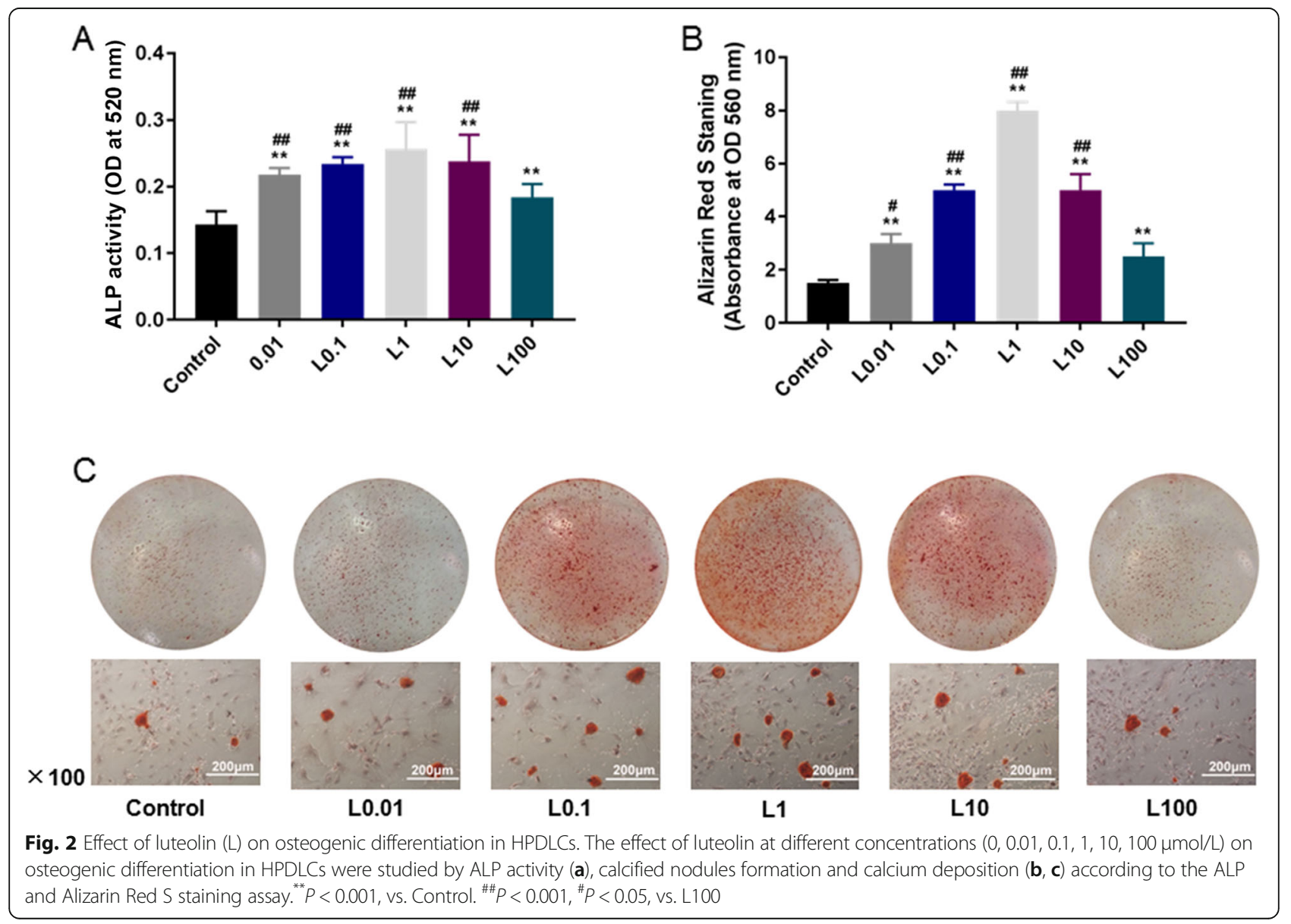




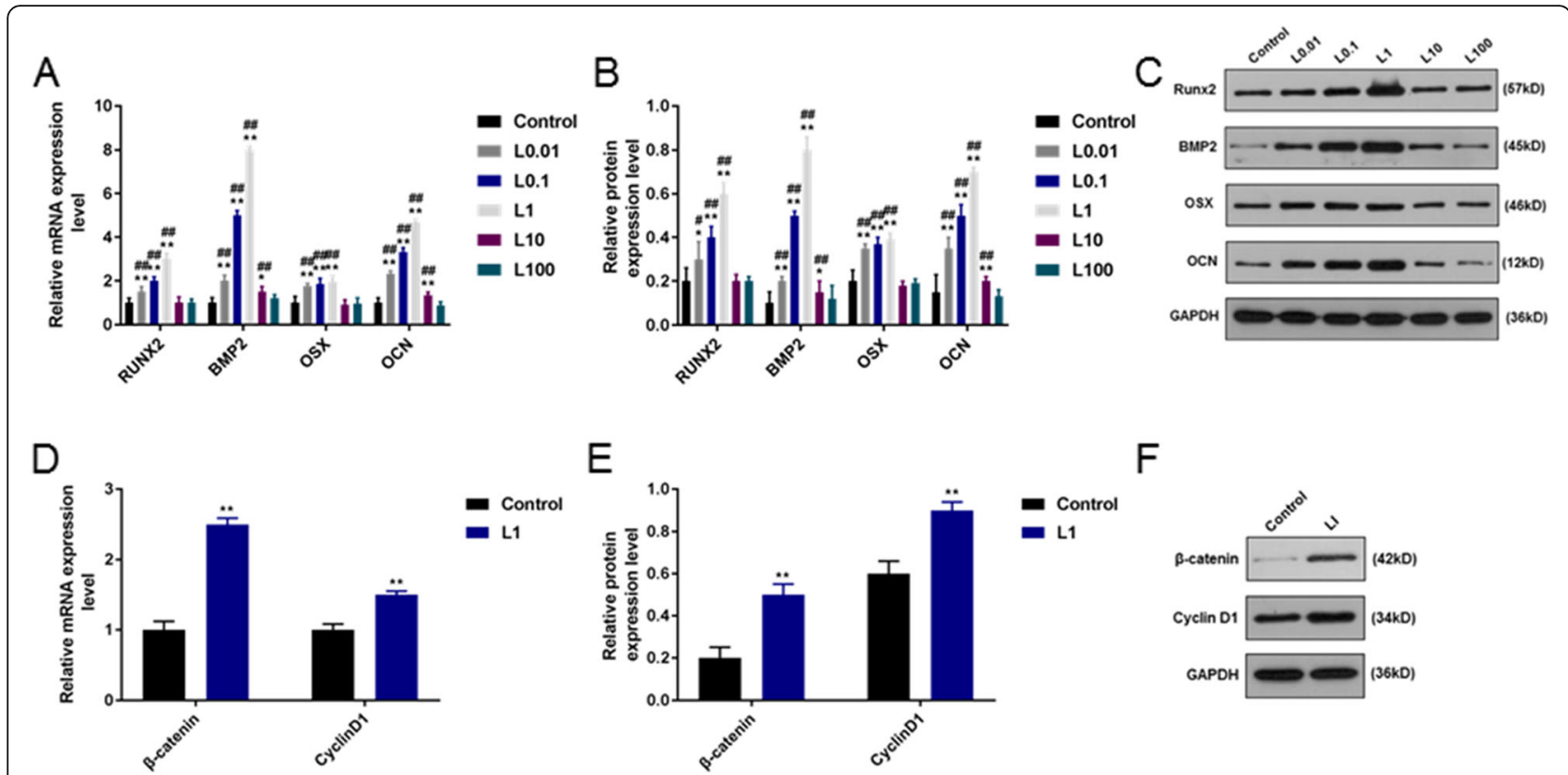

Fig. 3 Effect of luteolin (L) on the expressions of genes related to osteogenic differentiation and Wnt/ $\beta$-catenin pathway protein of HPDLCs. $\mathbf{a}$, $\mathbf{b}$, c qPCR and WB analyses of osteogenic differentiation-related genes (BMP2, OCN, RUNX2, OSX) and $\mathbf{d}$, e, $\mathbf{f}$ the expressions of Wnt/ $\beta$-catenin pathway proteins' (cyclin D1, $\beta$-catenin) in HPDLCs with the treatment of luteolin at different concentrations $(0,0.01,0.1,1,10,100 \mu \mathrm{mol} / \mathrm{L})$. ${ }^{* *} P<0.001,{ }^{*} P<0.05$, vs. Control. ${ }^{\# \#} P<0.001,{ }^{\#} P<0.05$, vs. L100

genes (BMP2, OCN, RUNX2 and OSX) $(P<0.001)$, while $5 \mu \mathrm{mol} / \mathrm{L}$ XAV939 greatly decreased the relative mRNA and protein expressions of osteogenic differentiationrelated genes $(P<0.001)$. Moreover, $1 \mu \mathrm{mol} / \mathrm{L}$ luteolin effectively reduced the inhibitory effect of XAV939 $(P<0.001$, Fig. 5a, b and c).

\section{Discussion}

HPDLCs, which are abundant in periodontal tissues, have multi-directional differentiation potential such as generating fibroblasts and osteoblasts and cementum cells [25]. Some studies confirmed that bone nodules could be formed from HPDLCs under certain condition, and that bone-related proteins such as ALP, bone sialoprotein, osteocalcin could also be expressed $[26,27]$. Furthermore, previous studies proved that periodontal tissue regeneration and repair was mainly dependent on the number and osteogenic differentiation ability of HPDLCs in periodontal tissue [28]. According Sun et al. [29], luteolin could alleviate the cytotoxicity induced by methylacetaldehyde, thus protecting MC3T3-E1 osteoblasts cells. Based on these studies, we speculated that luteolin had an effect of promoting osteogenic differentiation of HPDLCs. In addition, we also determined the optimal concentration of the drug and the related mechanism.

In this study, we investigated the characteristics of HPDLCs by immunofluorescence detection, the results revealed that vimentin staining was positive but keratin staining was negative, and our result was in line with a previous study [30], proving that the cells came from mesenchyme and the cell source was reliable. Then, luteolin at different concentrations were added to the HPDLCs and co-cultured, and the propagation capacity of the cells was detected by MTT assay. We found that luteolin at different concentrations could promote the generation of HPDLCs. However, the proliferation effect of luteolin on HPDLCs did not concern drug concentration, which might be explained by the significant difference in drug concentration gradient. In the following study, the concentration gradient can be reduced to the optimal medicine concentration.

ALP, which is a non-specific phosphomonoesterase, is generally present in human body, and it is a critical biomarker reflecting the osteogenic activity of cells. On the other hand, ALP, which can be used to examine the osteogenic differentiation function of HPDLCs, also plays an important role in cell mineralization [31], similarly, using Alizarin Red S staining is also a method for the detection of mineralization, especially in the measurement of late osteoblast differentiation impact [32]. Study by Lei et al. [33] demonstrated that the proliferation, osteogenic differentiation and mineralization of osteoblasts could be enhanced under some conditions. The results in our investigation revealed that 

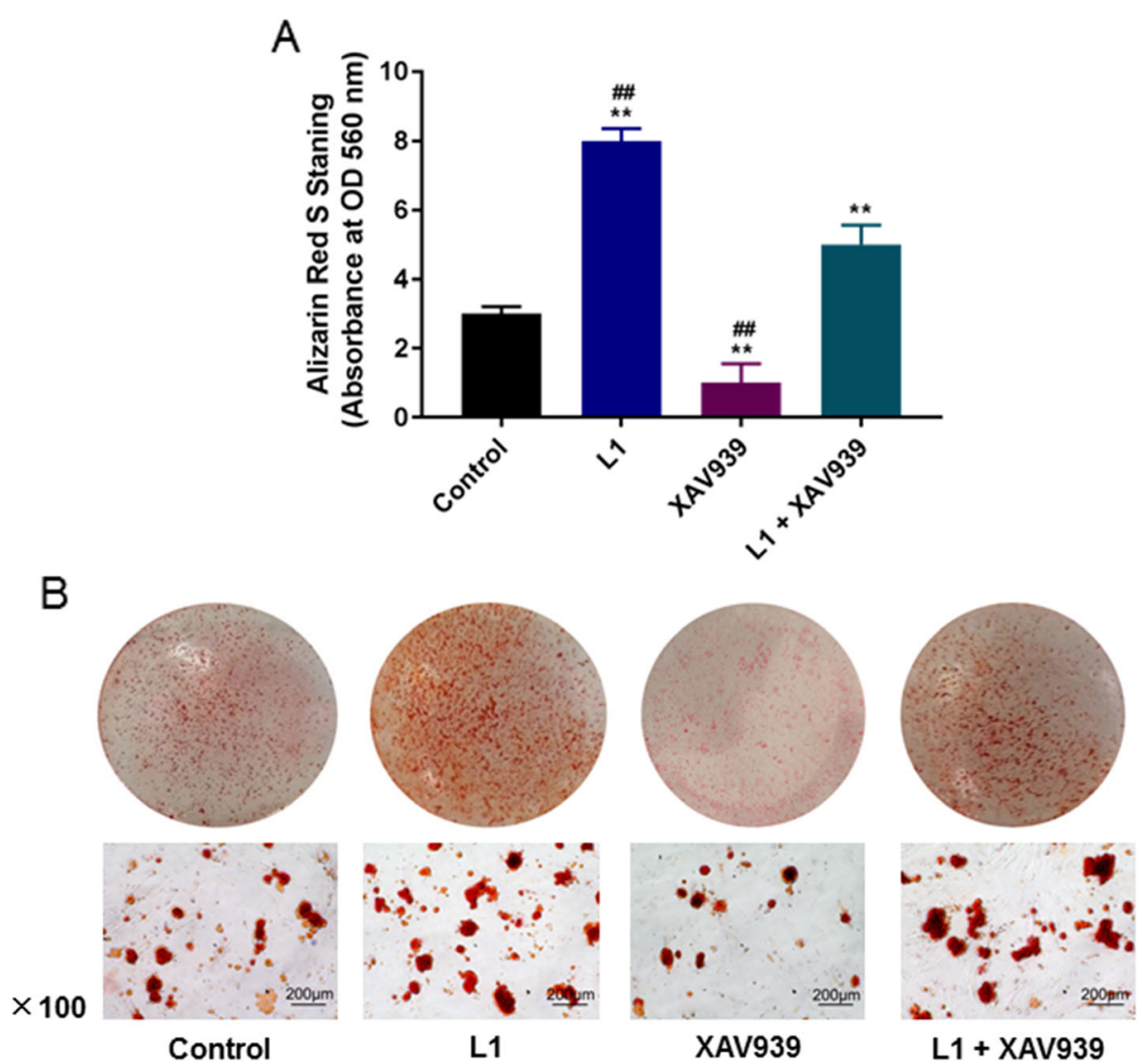

Fig. 4 Effect of Wnt/ß-catenin pathway inhibitor XAV939 on HPDLCS (L). $\mathbf{a}$, b Alizarin Red S staining was used to detect the formation of calcified nodules and calcium deposition in HPDLCs after treatment of $1 \mu \mathrm{mol} / \mathrm{L}$ luteolin, $5 \mu \mathrm{mol} / \mathrm{L}$ XAV939 or the combination of the two. ${ }^{* *} P<0.001$, vs. Control. ${ }^{\#} P<0.001$, vs. L1 + XAV939

luteolin at different concentrations could promote ALP activity and calcify nodules formation in HPDLCs, and that the effect of luteolin at low concentrations $(0.01$, $0.1,1,10 \mu \mathrm{mol} / \mathrm{L})$ was stronger, suggesting that a certain dose of luteolin could enhance the effect of mineralization and osteoblast differentiation in the cells. In animal models, Kim et al. [34] treated ovariectomized mice with luteolin, and found that luteolin could obviously increase the density and content of bone mineral in the femur of mice and reduce osteoclast differentiation. HPDLCs may comprise adult stem cells or subsets and have the effect of promoting osteogenic differentiation into osteoblasts under the effect of luteolin, resulting in a higher ALP activity and the development of a quantitative content of mineralized nodules.

Furthermore, qPCR and WB experiments were carried out to determine the expressions of genes. BMP2 is capable of inducing the differentiation of undifferentiated mesenchymal stem cells into chondroblasts and osteoblasts [35]. OCN is related to maturation of osteoblasts [36]. RUNX2 plays a significant role in the early proliferation of osteoblasts [37], and OSX is seated downstream of RUNX2 and also plays a key role in late osteoblastic differentiation and maturation [38]. Jia LI et al. [39] showed that luteolin could not only promote the osteogenic differentiation and proliferation of MC3T3-E1 cells, but also up-regulate the mRNA expression levels of RUNX2 and OCN. In this study, we demonstrated that luteolin at $0.01,0.1,1 \mu \mathrm{mol} / \mathrm{L}$ increased the correlative mRNA and protein expressions of BMP2, OCN, RUNX2 and OSX, and $1 \mu \mathrm{mol} / \mathrm{L}$ luteolin showed a relatively high performnace. Interestingly, $100 \mu \mathrm{mol} / \mathrm{L}$ of luteolin had no significant effects on the expressions of all osteogenic indicators, however, $10 \mu \mathrm{mol} / \mathrm{L}$ of luteolin increased the expressions of BMP2, OCN and OSX but did not have significant effect on the expression of RUNX2. Similarly, Liu L et al. [40] also found that luteolin affected the expressions of multipotent markers in dental pulp cells in a concentration-dependent manner. This proved 


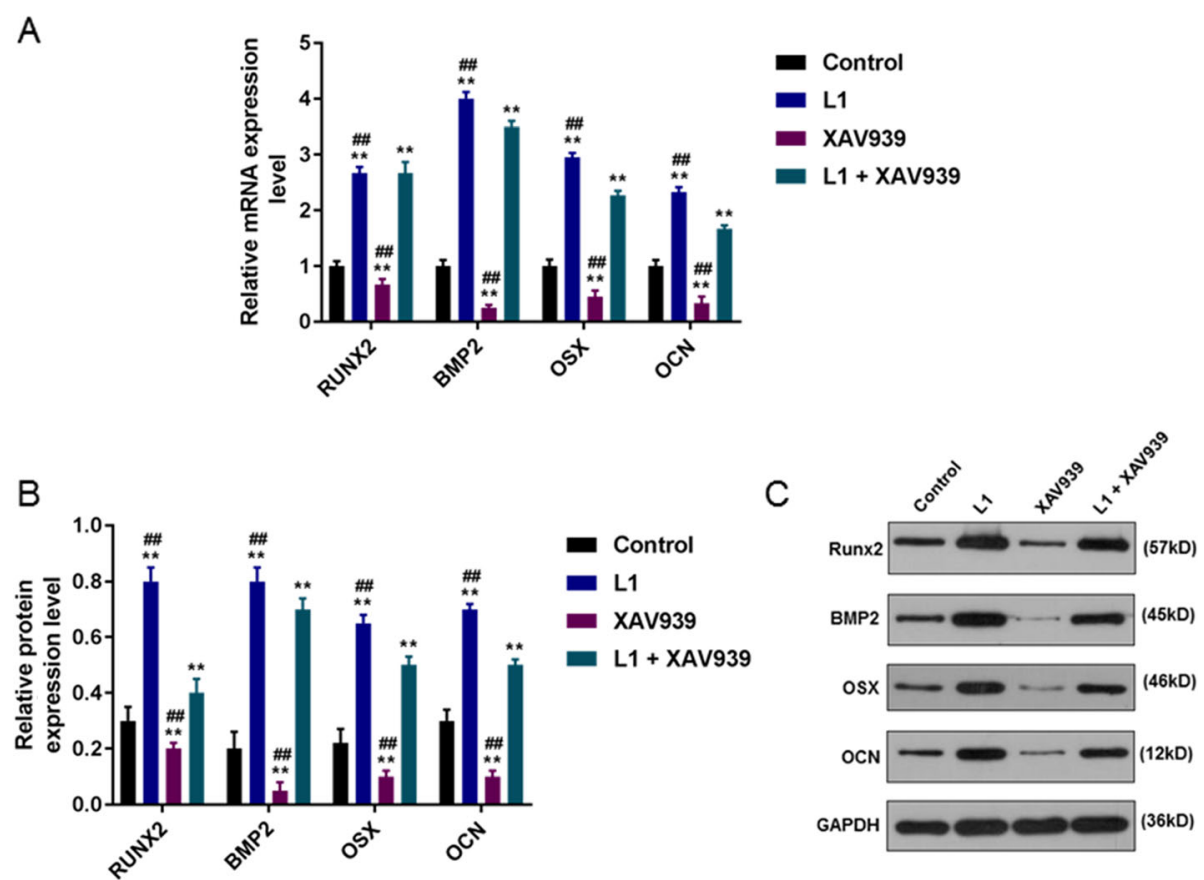

Fig. 5 Effect of Wnt/ß-catenin pathway inhibitor XAV939 on the expressions of genes related to osteogenic differentiation. a, b, c The expressions of BMP2, OCN, RUNX2 and OSX in HPDLCs after treatment of $1 \mu \mathrm{mol} / \mathrm{L}$ luteolin $(\mathrm{L}), 5 \mu \mathrm{mol} / \mathrm{L}$ XAV939 or combination of the two were detected through qPCR and WB assays. ${ }^{* *} P<0.001$, vs. Control. ${ }^{\# \#} P<0.001$, vs. L1 + XAV939

that luteolin at a certain concentration could activate osteogenic differentiation of HPDLCs.

As for the $\mathrm{Wnt} / \beta$-catenin signaling pathway, Rongrong et al. [41] discovered that $\mathrm{Wnt} / \beta$-catenin signal pathway could activate the expression of BMP2 in osteoblasts. This study indicated that luteolin at $1 \mu \mathrm{mol} / \mathrm{L}$ had the strongest effect on promoting osteogenic differentiation and it could obviously stimulate the production of $\beta$-catenin and cyclin D1, suggesting that luteolin might promote HPDLCs differentiation into osteoblasts via activating the $\mathrm{Wnt} / \beta$-catenin pathway. To further test our speculation, we used Wnt/ $\beta$-catenin pathway inhibitor (XAV939) to cultivate HPDLCs, and the result showed that XAV939 decreased the amount of calcified nodules and the expressions of genes related to osteogenic differentiation. Moreover, luteolin was found to relieve the inhibitory action of XAV939. According to the study data of Tian et al. [42], XAV939 decreased the death of neuroblastoma cell lines via controling the $\mathrm{Wnt} / \beta$-catenin pathway by blocking the signal pathway. Fujita et al. [43] also pointed out that XAV939 promoted the differentiation and maturation of osteoblasts in mice, which was reflected in the accessorial expressions of osteoblastrelated genes. These results verified that the inhibition of Wnt/ $\beta$-catenin could limit the differentiation of cells into osteoblasts.

\section{Conclusions}

In conclusion, luteolin at certain concentrations could promote the proliferation and osteogenic differentiation of HPDLCs, increase the expressions of genes related to osteogenic differentiation and activate the $\mathrm{Wnt} / \beta$-catenin pathway, noticeably, $1 \mu \mathrm{mol} / \mathrm{L}$ of luteolin had the strongest effect. Therefore, we recommended that luteolin of $1 \mu \mathrm{mol} / \mathrm{L}$ could be served as an optimal concentration to accelerate osteogenic differentiation of HPDLCs via activating the Wnt/ $\beta$-catenin pathway. Thus, our results contribute to the clinical application of periodontal disease.

\section{Abbreviations}

ALP: Alkaline phosphatase; BCA: Bicinchoninic acid; BMP2: Bone morphogenetic protein 2; CPC: Cetylpyridine chloride; DMEM: Dulbecco's modified eagle medium; EDTA: Ethylene diamine tetraacetic acid; FBS: Fetal bovine serum; HPDLCs: Human PDLCs; Nrf2: Nuclear factor erythroid 2related factor 2; OCN: Osteocalcin; OD: Optical density; OSX: Osterix; PBS: Phosphate buffer saline; PDLCs: Periodontal ligament cells; PMSF: Phenylmethanesulfonyl fluoride; PVDF: Polyvinylidene fluoride; GPCR: Quantitative polymerase chain reaction; RUNX2: Runt-related transcription factor 2; SD: Standard deviation; SDS-PAGE: Sodium dodecyl sulfate polyacrylamide gel electropheresis; TBST: Tris buffered saline tween

\section{Acknowledgements \\ None.}

Authors' contributions

Substantial contributions to conception and design: $H Q, X D$. Data acquisition, data analysis and interpretation: ML, CW, DW. Drafting the article or critically revising it for important intellectual content: DW, CW, ML. Final 
approval of the version to be published: All authors. Agreement to be accountable for all aspects of the work in ensuring that questions related to the accuracy or integrity of the work are appropriately investigated and resolved: $\mathrm{XD}, \mathrm{ML}$

\section{Funding}

None.

\section{Availability of data and materials}

The analyzed data sets generated during the study are available from the corresponding author on reasonable request.

\section{Ethics approval and consent to participate}

All procedures performed in studies involving human participants were in accordance with the ethical standards of the institutional and/or national research committee and with the 1964 Helsinki declaration and its later amendments or comparable ethical standards.

\section{Consent for publication}

Not applicable.

\section{Competing interests}

The authors declare that they have no competing interests.

Received: 20 February 2019 Accepted: 10 October 2019

Published online: 26 October 2019

\section{References}

1. Genco RJ, Borgnakke WS. Risk factors for periodontal disease. Periodontology. 2013;62(1):59-94.

2. Zhu W, Liang M. Periodontal ligament stem cells: current status, concerns, and future prospects. Stem Cells Int. 2015;2015:972313.

3. Moshaverinia A, Xu X, Chen C, Ansari S, Zadeh HH, Snead ML, Shi S. Application of stem cells derived from the periodontal ligament orgingival tissue sources for tendon tissue regeneration. Biomaterials. 2014;35(9):2642-50.

4. Yin-Hua Z, Min Z, Nan-Xia L, Xin L, Jing Z, Fa-Ming C, Yong-Jin C. The combined use of cell sheet fragments of periodontal ligament stem cells and platelet-rich fibrin granules for avulsed tooth reimplantation. Biomaterials. 2013;34(22):5506-20.

5. Wu Y, Wang Y, Ji Y, Ou Y, Xia H, Zhang B, Zhao Y. C4orf7 modulates osteogenesis and adipogenesis of human periodontal ligament cells. Am J Transl Res. 2017;9(12):5708-18.

6. Russell JO, Monga SP. Wnt/beta-catenin signaling in liver development, homeostasis, and pathobiology. Annu Rev Pathol. 2018;13:351-78.

7. Luttrell LM, Dar MS, Gesty-Palmer D, El-Shewy HM, Robinson KM, Haycraft CJ, Barth JL. Transcriptomic characterization of signaling pathways associated with osteoblastic differentiation of MC-3T3E1 cells. PLoS One. 2019;14(1):e0204197.

8. Kwon SM, Kim S, Song NJ, Chang SH, Hwang YJ, Yang DK, Hong JW, Park WJ, Park KW. Antiadipogenic and proosteogenic effects of luteolin, a majo dietary flavone, are mediated by the induction of DnaJ (Hsp40) homolog, subfamily B, member 1. J Nutr Biochem. 2016:30:24-32.

9. Jang SW, Cho CH, Jung YS, Rha C, Nam TG, Kim DO, Lee YG, Baek NI, Park $\mathrm{CS}$, Lee $\mathrm{BH}$, et al. Enzymatic synthesis of alpha-flavone glucoside via regioselective transglucosylation by amylosucrase from Deinococcus geothermalis. PLoS One. 2018;13(11):e0207466.

10. Wu G, Li J, Yue J, Zhang S, Yunusi K. Liposome encapsulated luteolin showed enhanced antitumor efficacy to colorectal carcinoma. Mol Med Rep. 2018;17(2):2456-64.

11. Wang JS, Yan HE, Zhang WJ, Zhang P, Huang QL, Hua ZC. Advances in studies on pharmacological effects of luteolin. Chin Bull Life Sci. 2013;25(6): 560-5.

12. Sugano N. Biological plaque control: novel therapeutic approach to periodontal disease. J Oral Sci. 2012;54(1):1.

13. Ming J, Zhuoneng L, Guangxun Z. Protective role of flavonoid baicalin from Scutellaria baicalensis in periodontal disease pathogenesis: a literature review. Complement Ther Med. 2018:38:11-8.

14. Murakami Y, Kawata A, Suzuki S, Fujisawa S. Cytotoxicity and Pro-/Antiinflammatory Properties of Cinnamates, Acrylates and Methacrylates Against RAW264.7 Cells. In vivo (Athens, Greece). 2018;32(6):1309-22.
15. Yang H, Liu Q, Ahn JH, Kim SB, Kim YC, Sang HS, Bang YH, Mi KL Luteolin downregulates IL-1ß-induced MMP-9 and -13 expressions in osteoblasts via inhibition of ERK signalling pathway. J Enzyme Inhib Med Chem. 2012;27(2):261-6.

16. Nash LA, Sullivan PJ, Peters SJ, Ward WE. Rooibos flavonoids, orientin and luteolin, stimulate mineralization in human osteoblasts through the Wnt pathway. Mol Nutr Food Res. 2015;59(3):443-53.

17. Abbasi N, Khosravi A, Aidy A, Shafiei M. Biphasic response to Luteolin in MG-63 osteoblast-like cells under high glucose-induced oxidative stress. Iran Jed Sci. 2016;41(2):118-25.

18. Liu L, Peng Z, Huang H, Xu Z, Wei X. Luteolin and apigenin activate the Oct-4/Sox2 signal via NFATc1 in human periodontal ligament cells. Cell Biol Int. 2016:40(10):1094-106.

19. Chen LJ, Hu BB, Shi XL, Ren MM, Yu WB, Cen SD, Hu RD, Deng H. Baicalein enhances the osteogenic differentiation of human periodontal ligament cells by activating the Wnt/ $\beta$-catenin signaling pathway. Arch Oral Biol. 2017;78:100-8

20. Xiao Z, Han Y, Zhang Y, Zhang X. Hypoxia-regulated human periodonta ligament cells via Wnt/beta-catenin signaling pathway. Medicine. 2017; 96(16):e6562.

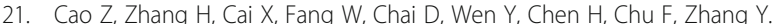
Luteolin promotes cell apoptosis by inducing autophagy in hepatocellular carcinoma. Cell Physiol Biochem. 2017;43(5):1803-12.

22. Si H, Wyeth RP, Liu D. The flavonoid luteolin induces nitric oxide production and arterial relaxation. Eur J Nutr. 2014;53(1):269-75.

23. Renna C, Salaroli R, Cocchi C, Cenacchi G. XAV939-mediated ARTD activity inhibition in human MB cell lines. PLoS One. 2015;10(4):e0124149.

24. Rao X, Huang X, Zhou Z, Lin X. An improvement of the $2 \ddot{E}+$ (-delta delta CT) method for quantitative real-time polymerase chain reaction data analysis. Biostat Bioinforma Biomath. 2013:3(3):71-85.

25. Nomura $Y$, Yashiro $Y$, Sanggarnjanavanich S, Yamaguchi T, Arai C, Noda K, Takano Y, Nakamura Y, Hanada N. Human periodontal ligament fibroblasts are the optimal cell source for induced pluripotent stem cells. Histochem Cell Biol. 2012:137(6):719-32.

26. Kim SE, Yun YP, Han YK, Lee DW, Ohe JY, Lee BS, Song HR, Park K, Choi BJ. Osteogenesis induction of periodontal ligament cells onto bone morphogenic protein-2 immobilized PCL fibers. Carbohydr Polym. 2014; 99(1):700-9.

27. Moritani Y, Usui M, Sano K, Nakazawa K, Hanatani T, Nakatomi M, Iwata T, Sato T, Ariyoshi W, Nishihara T, et al. Spheroid culture enhances osteogenic potential of periodontal ligament mesenchymal stem cells. J Periodontal Res. 2018:53(5):870-82.

28. Liu D, Wang Y, Jia Z, Wang L, Wang J, Yang D, Song J, Wang S, Fan Z Demethylation of IGFBP5 by Histone Demethylase KDM6B Promotes Mesenchymal Stem Cell-Mediated Periodontal Tissue Regeneration by Enhancing Osteogenic Differentiation and Anti-Inflammation Potentials. Stem cells (Dayton, Ohio). 2015;33(8):2523-36.

29. Suh KS, Chon S, Choi EM. Luteolin alleviates methylglyoxal-induced cytotoxicity in osteoblastic MC3T3-E1 cells. Cytotechnology. 2016;68(6):2539-52

30. Chopra H, Liao C, Zhang CF, Pow EHN. Lapine periodontal ligament stem cells for musculoskeletal research in preclinical animal trials. J Transl Med. 2018;16(1):174

31. Qin W, Chen JY, Guo J, Ma T, Weir MD, Guo D, Shu Y, Lin ZM, Schneider A Xu HHK. Novel calcium phosphate cement with metformin-loaded chitosan for Odontogenic differentiation of human dental pulp cells. Stem Cells Int. 2018;2018:7173481.

32. Zhou Y, Fan W, Xiao Y. The effect of hypoxia on the stemness and differentiation capacity of PDLC and DPC. Biomed Res Int. 2014;2014:890675.

33. Lei $Q$, Lin $D$, Huang WX, Wu D, Chen J. Effects of calcium ion on the migration and osteogenic differentiation of human osteoblasts. Hua Xi Kou Qiang Yi Xue Za Zhi. 2018;36(6):602-8.

34. Kim TH, Jung JW, Ha BG, Hong JM, Park EK, Kim HJ, Kim SY. The effects of luteolin on osteoclast differentiation, function in vitro and ovariectomyinduced bone loss. J Nutr Biochem. 2011;22(1):8-15.

35. Song R, Wang D, Zeng R, Wang J. Synergistic effects of fibroblast growth factor-2 and bone morphogenetic protein-2 on bone induction. Mol Med Rep. 2017;16(4):4483-92.

36. Anna N, Addolorata C. Francesco Paolo C. Osteocalcin: skeletal and extraskeletal effects. J Cell Physiol. 2013;228(6):1149-53.

37. Toshihisa K. Signaling networks in RUNX2-dependent bone development. J Cell Biochem. 2015;112(3):750-5. 
38. Farshdousti Hagh M, Noruzinia M, Mortazavi Y, Soleimani M, Kaviani S, Abroun S, Dehghani Fard A, Mahmoodinia M. Different methylation patterns of RUNX2, OSX, DLX5 and BSP in Osteoblastic differentiation of Mesenchymal stem cells. Cell J. 2015;17(1):71-82.

39. Li J, Lin X, Zhang Y, Liu W, Mi X, Zhang J, Su J. Preparative Purification of Bioactive Compounds fromFlos Chrysanthemi Indiciand Evaluation of Its Antiosteoporosis Effect. Evid Based Complement Alternat Med. 2016;2016(3):1-12.

40. Liu L, Peng Z, Xu Z, Wei X. Effect of luteolin and apigenin on the expression of Oct-4, Sox2, and c-Myc in dental pulp cells with in vitro culture. Biomed Res Int. 2015;2015:534952.

41. Rongrong Z, Oyajobi BO, Harris SE, Di C, Christopher T, Hong-Wen D, Ming Z. Wnt/ $\beta$-catenin signaling activates bone morphogenetic protein 2 expression in osteoblasts. Bone. 2013;52(1):145-56.

42. Tian XH, Hou WJ, Fang Y, Fan J, Tong H, Bai SL, Chen Q, Xu H, Li Y. XAV939, a tankyrase 1 inhibitior, promotes cell apoptosis in neuroblastoma cell lines by inhibiting Wnt/ß-catenin signaling pathway. J Exp Clin Cancer Res. 2013; 32(1):100.

43. Fujita S, Mukai T, Mito T, Kodama S, Nagasu A, Kittaka M, Sone T, Ueki Y, Morita Y. Pharmacological inhibition of tankyrase induces bone loss in mice by increasing osteoclastogenesis. Bone. 2018;106:156-66.

\section{Publisher's Note}

Springer Nature remains neutral with regard to jurisdictional claims in published maps and institutional affiliations.

Ready to submit your research? Choose BMC and benefit from:

- fast, convenient online submission

- thorough peer review by experienced researchers in your field

- rapid publication on acceptance

- support for research data, including large and complex data types

- gold Open Access which fosters wider collaboration and increased citations

- maximum visibility for your research: over $100 \mathrm{M}$ website views per year

At $\mathrm{BMC}$, research is always in progress.

Learn more biomedcentral.com/submissions 